\title{
It Is Necessary to Resist
}

History tells that a few weeks after United States drops the atomic bombs in Hiroshima and Nagazaki, finishing the II World War, the Nobel Prize winner Linus Pauling starts to give speeches to different kinds of audiences, with the purpose of making the scientific issues related to the bomb understandable to the public. As an eminent scientist in the nuclear field, Pauling had been previously invited to join the Manhattan Project at their beginning, but he had refused. Pauling was convinced that the nascent atomic age imputed strong political responsibilities to the scientists, and he worked hard to stop the nuclear proliferation, which resulted in his indication to the Peace Nobel Prize several years after, in 1962. At that time Pauling declared: "I feel that, in addition to our professional activities, we should make our voices known with respect to the political significance of science."

The political significance of science is immensurable. As everyone should know, all the advances experimented by the humanity since the beginning of civilization is result of the application of scientific knowledge. The domain of science has a deep influence on both the welfare of the citizens and the social development of a nation, and it is close related to the socioeconomic, cultural, geographic, demographic, health and environmental issues, among others. It's not a coincidence that the Governments of different countries are increasing the public investments in Science and Technology (S\&T) as a strategy to overcome the global economic crises. China, for example, announced a boost in its S\&T program, increasing in almost $9 \%$ of the investment in 2016, and betting that innovation will be responsible for the economic development of the country.

Unfortunately, Brazil is rowing in the opposite side of the history, and taking to account the recent actions, the scenario for the near future tends to get worse. The Brazilian scientific community has seen in the last two decade a slow but continuous fortification of the entire system of S\&T through the entire country, marked by an expansion and decentralization of public Federal Universities; by the creation and improvement of laboratorial and equipment infrastructure; by the increase of the percentage of the GDP invested in S\&T; by the consolidation of the national graduate program coordinated by CAPES, the agency directly subordinately to the Ministry of Education; among several other issues. However, all these achievements are threatened. In an incredible sequence of recent events, the Brazilian Scientific community was surprised by the extinction of the Federal Ministry of Science, Technology and Innovation (MCTI), which was fused to the Ministry of Communications; by the cut of $20 \%$ of the undergraduate fellowship offered by CNPq, the main Brazilian agency of fomentation of S\&T; by the cut of fellowship for students and researchers to get their PhD or Posdoc abroad; by several research calls frozen without transference of the resources from the agencies to the laboratories and research institutes; by the reduction of investments for the national graduate programs, which are responsible for the majority of the S\&T produced in Brazil; by a proposal of $45 \%$ of reduction in the budget of the Federal Universities in 2017, which would strongly affect the scientific production, since almost $90 \%$ of the Brazilian science is produced at Universities; by several other actions at different levels that demonstrate the neglect in which the S\&T has been recently treated.

Brazil cannot go back. Brazil is going through an economic, politic and institutional crisis, and a robust investment in Education and S\&T is a natural and cheap way to begin the reversion of this situation. The prevention of this setback is responsibility of all the actors directly involved in the National System of Education, Science, Technology and Innovation. Students, professors, researchers, posdocs, technicians, and their representative unions should urgently fight against the squeeze of the budget destined to S\&T. The scientific societies such as the Brazilian Chemical Society have a crucial role in this process. It is necessary to demonstrate to the politicians and to the general public that S\&T are strategic to the socioeconomic development of the country. It is necessary once more to learn with Linus Pauling, and "make our voices known with respect to the political significance of science." It is necessary to resist.

Aldo José Gorgatti Zarbin President of the Brazilian Chemical Society 